\title{
Article \\ Open Innovation Competence for a Future-Proof Workforce: A Comparative Study from Four European Universities
}

\author{
Marita McPhillips * (D) and Magdalena Licznerska \\ Faculty of Management and Economics, Gdansk University of Technology, 80-233 Gdansk, Poland; \\ magdalena.licznerska@pg.edu.pl \\ * Correspondence: marita.mcphillips@pg.edu.pl
}

check for updates

Citation: McPhillips, M.; Licznerska, M. Open Innovation Competence for a Future-Proof Workforce: A Comparative Study from Four European Universities. J. Theor. Appl. Electron. Commer. Res. 2021, 16, 2442-2457. https://doi.org/ $10.3390 /$ jtaer16060134

Academic Editors:

Vahid Jafari-Sadeghi and Hannan Amoozad Mahdiraji

Received: 5 August 2021

Accepted: 14 September 2021

Published: 18 September 2021

Publisher's Note: MDPI stays neutral with regard to jurisdictional claims in published maps and institutional affiliations.

Copyright: (c) 2021 by the authors. Licensee MDPI, Basel, Switzerland. This article is an open access article distributed under the terms and conditions of the Creative Commons Attribution (CC BY) license (https:/ / creativecommons.org/licenses/by/ $4.0 /)$.

\begin{abstract}
Digital transformation is a key driving force of open innovation to capture and transfer knowledge inside and outside of a company's bounds. New challenges in organizing multiple knowledge flows imply the need for increased competences related to this paradigm of future employees. In this article, we organize and aggregate the competencies required for open innovation collaboration and develop a competence profile that organizes individual competencies in an open innovation context. Based on elements of the European Entrepreneurship Competence Framework, we delineate an OI Competence Profile and list the core competencies to manage and accelerate the inflow and outflow of knowledge. We explore this profile by comparing data from 2332 students from four European universities to find differences in the distribution of OI competencies between countries. The study contributes to understanding the individual competencies that target the future OI needs of companies necessary in the context of digital transformation. It also introduces an interdisciplinary approach to integrate the research streams of management practice, open innovation, and entrepreneurial education.
\end{abstract}

Keywords: digital transformation; open innovation; competence

\section{Introduction}

Digital transformation manifests changes in the global information economy rising from the advancement of digital technologies, ubiquitous innovation, intellectual work mobility, and the growing importance of information sources and processes [1]. To take advantage of the transformation and create a sustainable, future-ready employee environment, companies need to identify employees who are motivated by and skilled in digital transformation. According to the European Commission [2], education, training, reskilling, and upskilling are among the most urgent concerns to address when adjusting to the digital transformation in industries, as a competent workforce is of the ultimate importance to make it a reality. The World Manufacturing Forum [3] has determined the top ten skills that will be essential in future industries. Notably, only four of them relate directly to digital skills. The remaining are more transversal abilities linked to creative, entrepreneurial, flexible, and open-minded thinking.

The concept of open innovation (OI) is defined as the use of purposive inflows and outflows of knowledge to accelerate internal innovation and expand the markets for external use of innovation [4]. It implies that two or more organizations are jointly engaged in an integrated effort to generate new solutions and shape them into a product or process by linking various types of technology, concepts, skills, and means [5]. Primarily, OI has been incorporated by large multinational organizations [6] and SMEs [7]. It is apparent that the role of OI has become more vital, contributing to the creation of new OI employment characteristics in firms [8]. Future employees involved in OI projects must therefore have, learn, and expand competencies distinct to this paradigm [9]. OI employees have distinct attitudes and abilities to co-create solutions mobilizing innovation ecosystems [10]. They possess the competencies to learn again and discover new ways to apply external 
knowledge, making it "absorbable" [11], looking for external knowledge, helping the ideas through internal processes, and supporting their exploitation in the organization $[4,12]$.

There is a vast amount of literature on barriers for the management of a workforce engaged in knowledge acquisition and boundary-broadening activity [9,13-15]. Similarly, numerous scholars have explained managerial practices to implement OI [16,17]. Still, OI literature has not made clear how future employees could prepare to face the challenges of OI, and there is a lack of research on how OI activities are managed at the individual level [18], given that the success of OI strategies hinges on the employees appointed to execute these strategies. For instance, the study by Enkel [17] presents different firm-level capabilities and processes that firms need to develop to fully adopt open innovation; their study does not suggest how to develop OI capabilities. Vanhaverbeke and Cloodt [19] pointed out the limited research on OI managerial practices as a basis to develop OIoriented entrepreneurial education.

Companies depend on the research and knowledge of universities to prepare their employees and manage innovation. This research takes on the challenge of disentangling the OI competencies that university students of different fields should acquire to benefit from the inflow and outflow of knowledge as future OI employees. Although much effort has been made to encourage being innovative, especially among young people, many students who have already graduated from universities do not consider themselves innovative [20,21]. Developing young adults' OI competences is still a challenging task [22].

The research question of this paper is: What competencies are required for the open innovation collaboration of the future workforce? The aim of this paper is to identify those competencies and develop a competency profile that organizes individual competencies in an open innovation context. We further explore this profile by comparing data from students from four European universities to find differences in the distribution of OI competences across countries.

We investigate a large sample of students, with a focus placed on students from four countries evaluated as transition economies. A transition economy is an economy that is changing from a centrally planned to a market economy [23]. Up until recently, the majority of studies on OI were carried out in advanced market economies. The prominence of a transition economy context is substantiated as the institutional environment forms the structure of political, social, and economic stimulus, and thereby restricts the breadth of the strategic choices available to employees and companies and determines the use of OI practices by organizations [24]. It is believed [25] that empirical gaps need to be filled to understand processes that can overcome the low level of trust in order to expedite collaboration in an OI context.

The innovation process in transition economies is determined by both the level of technological and market complexity, and the institutions, infrastructure, and framework conditions where firms operate. According to The Global Innovation Index 2020 [26], all four researched countries performed similarly in the overall rank: Latvia ranks 23rd among the 39 economies in Europe, Bulgaria ranks 24th, Poland 25th, and Ukraine 30th. Despite lower ranks in the overall score, relative to GDP, Ukraine is performing above expectations, and Poland, gaining a high-income group economy status only in 2018 and having been a middle-income group economy for the previous 15 years, underperforms expectations for its level of development. We can assume a similar innovation level of these countries, which makes a strong base for comparisons among them.

All of the countries studied here are transition economy countries still experiencing driving forces, defined as the path dependence shaping systemic changes. Taking the perspective of path dependence, transformation is defined as the process of accumulation of positive or negative effects, the result of which is influenced to a greater extent by actions undertaken in the old system than those undertaken in a later period [27]. It has created specific patterns of behavior both in relation to the adopted institutional solutions used in the economy and politics and in social attitudes that cannot be ignored. 
The conclusions augment theoretical links between entrepreneurial competency management and open innovation management and give recommendations pointing to how employees can support the success of OI [18]. Additionally, the results fuel the knowledge base for entrepreneurial education toward future needs in open innovation, transforming the economy. Even though this paper is exploratory, the study utilizes quantitative data based on an original survey.

The paper is structured as follows. In the theoretical part of this paper, the competencies supporting OI are described. Since we included certain elements in the OI competency profile, its description is followed by a review of literature pertaining to creativity, cooperation, and entrepreneurial attitudes. We believe that the unique way in which all the elements studied mentioned above are taken into consideration, brought together and used in one proposed competence profile, can be seen as a promising and underexplored avenue for individual motivations toward digital transformation research. Therefore, the intended contribution to be made is related to an expansion of the current understanding of what OI competencies look like in an under-researched regional context.

The theoretical part of the paper is followed by a description of an exploratory study in which the elements of the theory were tested on a group of university students from Bulgaria, Latvia, Poland, and Ukraine. Students in their first year of study were included. The Kruskal-Wallis test was used, and significant differences were found. Apart from the contribution related to the theory development, this article can contribute to the understanding of factors influencing the emergence of open innovation skills and individual motivations towards digital transformation in the European context, and specifically in its eastern and central part. The economies studied are functioning in the post-communist era and are trying to expand by using free-market mechanisms. To stimulate this growth in the future, it is crucial to encourage young adults to develop open innovation skills. The article is concluded with a discussion of the implications of the obtained findings, and further research avenues are proposed.

\subsection{Competencies in Support of OI}

Open innovation includes a broad array of types and scopes of activities in innovation projects [28]. Firms are involved in outbound innovation (through disclosing or trading know-how) or in inbound innovation (through sourcing or securing knowledge from outside) [29], or in both (by combining external innovation assets and outbound transfer activity) [30]. A fundamental theoretical structure for analyzing and categorizing the competency angle of innovation processes is the exploration/exploitation dichotomy, implying that the individual competencies associated with both modes are critical for succeeding in OI [31].

The specific OI competency follows the demand for firms to form and govern innovation process beyond ecosystem bounds, bringing together various sources of inbound and outbound expertise within varied and strenuous innovation projects. Tapping into the crucial urgency to apply applicable expertise throughout company bounds, as identified in previous studies [32,33], companies are dependent on different arrays of competencies to govern the scale of openness as a practice of managing the barriers for OI at the employee level [18].

This complements the calls [18] for studies at the intra-organizational level of analysis that will reveal how individual-level capabilities, as well as the structure of the firm, need to adjust to the OI paradigm. The barriers to carrying out OI collaboration put new strains on the competencies of the participating employees. Still, it is challenging for companies to determine and obtain these abilities and skills in new employees [34].

In this paper, we define competence as a mixture of the type of work and the attributes of the employee carrying it out [35]. A competency (plural competencies) is a part of competence, which is the employees' array of distinct expertise, insight, and skills/capabilities/behaviors that allow them to manage the challenges and obligations of their work [36,37]. Therefore, our study concentrates on investigating and empirically eval- 
uating competencies as the basic unit of analysis and as the components of competences. In our study, we aim attention at analyzing the general competencies for OI, while not differentiating skills and abilities in the literature review and the subsequent operationalization of the concept.

An unambiguous attribution of individual competencies to the features of OI and its stages, the exploration and exploitation of knowledge, is not without its challenges. Therefore, in this study, we try to organize and aggregate the most dominant traits identified in the literature as encouraging OI activity on the individual level.

A study of large multinationals [38] proposed a set of desirable personal abilities, including open attitude, a business mindset (entrepreneurship), adaptability, and flexibility (cooperation) [34]. Du Chatenier et al. [9] identified three dimensions needed for effective involvement of employees in open innovation projects: managing inter-organizational innovation (cooperation), managing the overall innovation process (entrepreneurship), and creating knowledge collaboratively (creativity, collaboration).

According to Hafkesbrink and Schroll [31], on the side of exploration, individual competencies are needed that help employees capture new knowledge: creativity, initiative, commitment, curiosity, flexibility. On the exploitation side, individual competencies should encourage the utilization of knowledge; thus, the share of creativity may be lower, and individual competencies that are needed are those that support persistence, strength of character, ambition, diligence, execution, and reliability (entrepreneurship). Correspondingly, cooperation-related competencies are needed to balance the inevitable constrictions of exploration and exploitation.

A study on 473 SMEs from Poland [39] indicated three dimensions representing innovative culture supporting open innovation: creativity and risk taking, internal cooperation, and learning abilities. In a study of the open innovation competency of design companies [40], individual open innovation competency of individuals was defined with three qualities: creativity, organizing ability (entrepreneurship), and expressive ability.

Another study [41] points to the exploring phase, which requires cooperation and creativity competences, listening to and engaging with other people in order to find new insights and using it to recognize and address new needs. The exploitation phase requires cooperation, creativity, and entrepreneurship skills for extracting and implementing, that is, collaborating with others to develop the ideas, test them, and create prototypes.

Kratzer et al. [42] argue that setting employees' mindsets mainly on the creative side of open innovation might be misleading: employees may be eager to generate ideas (creativity) and engage in open projects, but they might not see the aim of the project to use the innovation in many ways. This indicates that an open innovation culture should cover the whole extent of the innovation process, underlining the application of good solutions by the employees regardless of the idea source (cooperation), and they should possess competencies that support implementation (entrepreneurship). Matricano [43] believes that the success of open innovation is built on competencies such as curiosity, creativity, flexibility, and diversity, because the open dimension requires openness (cooperation), trust, responsibility (entrepreneurship), authenticity, and sustainability.

Csath [44] argues that understanding open innovation is critical for SMEs to grow, and there is a need for an educational system that supports creativity, self-discipline, selfmotivation (entrepreneurship), desire for knowledge and lifelong learning, openness, and cooperation. The study mentioned implies that an encouraging external environment and a supporting internal learning atmosphere are both significant for effective innovation in small and medium companies.

Podmetina et al. [8] proposed types of OI that are based on distinct competencies for their achievement, specifically, open technology acquisition and transfer, open mass innovation, and open cooperative innovation. They suggested that a specific OI management competency needs a suitable set of cultural consciousness, skills to cooperate with different communities, ability to create knowledge (creativity) as well as distribute and receive knowledge, and ease to work in a multidisciplinary environment and on cross-functional 
projects, integrated with communication and networking ability (cooperation). Moreover, interpersonal OI competencies included innovation process collaboration and innovative project management (entrepreneurship).

It is self-evident that creativity as an individual skill has had the broadest representation in open innovation literature as a critical competence. However, there is also a wide consensus on entrepreneurship as a skill needed for the successful application of innovation. The idea of culture for open innovation is often defined as the interaction between different facets of entrepreneurialism: the entrepreneurship of new entrepreneurs, the intrapreneurship of project members in an existing company, and organizational entrepreneurship by the company itself [45]. Cheng and Huizingh [46] studied 223 Asian service companies and found that strategic orientation is a significant and positive moderator between open innovation and company's performance in terms of innovation, with entrepreneurial orientation strengthening the positive effect more than market or resource orientation. Critical dimensions defining entrepreneurial orientation were proactiveness, risk tolerance, creativity, and intensive support for innovation process.

In an open innovation context, the entrepreneur's mindset seems to moderate the personal opportunity recognition and commercialization, thus positively influencing the likelihood of new venture/project survival [47]. The entrepreneurial mindset does not in itself lead to project success-it does not generate or transfer any resources by itself. Rather, it increases the effectiveness of individual relationships and transactions with stakeholders. Similarly, simply having access to stakeholders does not lead to success, but an entrepreneurial mindset will help the individual identify valuable sources of knowledge and recombine them into successful innovation.

Subsequently, a great deal of attention is paid in the OI literature stream to cooperation in its broad meaning. Behanm et al. [48] identify four competences as bundles of open innovation cooperation capabilities, namely networking, competency mapping, relational, and desorptive capabilities. Bello-Pintado and Bianchi [49] point to social skills connected to open innovation strategies and define them as cooperation and communication abilities, which are potentially related to formal education but are mainly based on personal features and grounded by experience in different contexts. According to Kratzer et al. [42], successful teamwork in an open innovation context involves integrating complementary knowledge and skills to utilize the innovation potential of cooperating employees with diverse social backgrounds (cooperation). In such situations, knowledge holders with different social backgrounds could be brought together by adapting personal knowledge to the particular institutional and regional circumstances, which is a time-consuming yet critical process, and therefore should be integrated into an open innovation team from the start.

Summing up, the empirical evidence in the OI research stream points to the aggregated competencies of creativity, entrepreneurship, and cooperation as multifaceted constructs supporting OI activity.

\subsection{Open Innovation Competence Profile of University Students as Future Workforce}

In our study, the open innovation concept builds on entrepreneurial learning in several ways: progressing broad self-reliance and capacity to pursue ideas and opportunities to generate value, as well as developing the ability to create value from elementary and predictable frameworks to sophisticated, rapidly changing environments. Moreover, our research hypotheses were formulated concerning the elements of the Open Innovation competence profile adopted in the context of digital transformation. We conduct our research on groups of students from technological universities as a future workforce for European companies. In order for employers to be ready to successfully navigate and succeed in an ever-changing work landscape, students, as future employees, must be prepared to enter this digital transformation process. Thus, our research focuses on these young adults. 
The present study examines the positioning of students towards open innovation in terms of their self-perceived skills and abilities. Questions were asked about different kinds of skills and motivations that are associated with OI competences. In consonance with the prevalent employability discussion, it was anticipated that features describing entrepreneurship, creativity, and cooperation in particular would show no differences between different countries with similar cultural and historical contexts.

Taking the above into account, we proposed an OI competence profile of university students, which reflects the ability of university students to manage processes associated with OI $[8,9,31,39,41-46]$ :

- Entrepreneurial competency, which is important for any innovation specialist, assisting in productive and collaboration in an OI paradigm;

- Creative work competency, which is necessary for transferring creative solutions into products that are likely to thrive in a changing and volatile environment;

- Cooperation competency, which is needed for developing the right combination of skills to distribute and receive knowledge, ability to perform in diverse circumstances, and management of multi-functional projects.

Those skills were identified and aggregated as the most prevalent skills in the empirical OI studies corresponding to the needs of the OI paradigm. The selection criteria of competencies ensured that the aggregated constructs reflect the given definition of competence and correspond to the challenges of open innovation, and that there should be empirical evidence pointing to their importance for open innovation processes. Although these competencies, as such, may not be treated as an exclusive qualification for the OI professional, they help to gain and integrate outside knowledge in internal processes and external use. Separately, these competencies could be considered substantial for any OI project employee and for intra-organizational innovation. However, together with other competencies, they become critical elements in the comprehensive competence of OI professionals in such processes.

For the purpose of our study, we adapt elements of The European Entrepreneurship Competence Framework [50], a flexible reference framework to support the development and understanding of entrepreneurial competence in a context of open innovation. The European Entrepreneurship Competence Framework was developed by the European Commission as a reference framework to explain what is meant by an entrepreneurial mindset. In our study, we operationalize skills as aggregated constructs based on the corresponding skills definitions from the Framework. Subsequently, an OI competence profile was constructed (Table 1), based on the list of three aggregated competencies, supported and grounded in relevant OI empirical studies. After that, a profile was compared using data raised among students from three universities.

Table 1. Open Innovation Competence Profile and corresponding skills from European Entrepreneurship Competence Framework.

$\begin{array}{cc}\begin{array}{c}\text { Open Innovation Competence Profile } \\ \text { (and Respective Questions from the Survey) }\end{array} & \begin{array}{c}\text { Corresponding European Entrepreneurship } \\ \text { Competence Framework Skills [37] }\end{array} \\ \begin{array}{c}\text { "Valuing ideas } \\ \text { Entrepreneurship }\end{array} & \begin{array}{c}\text { Judging what value is in reference to social, cultural, and economic } \\ \text { conditions } \\ \text { Recognising the potential of an idea to generate value and finding unique } \\ \text { ways to capture that value" } \\ \text { "Spotting opportunities }\end{array} \\ \begin{array}{c}\text { I can develop a unique idea for a business. } \\ \text { I can identify market opportunities for a new } \\ \text { business. }\end{array} & \begin{array}{c}\text { Identifying and taking advantage of opportunities to generate value by } \\ \text { examining the social, cultural and economic environment } \\ \text { I feel I am an entrepreneurial person. }\end{array} \\ \begin{array}{c}\text { Identifying problems, needs and challenges that need to be solved. } \\ \text { Establishing new ways of connecting and combining different parts of } \\ \text { the environment to generate value" }\end{array}\end{array}$


Table 1. Cont

Open Innovation Competence Profile (and Respective Questions from the Survey)

Cooperation

I can convince others to work for me in my new business.

I can work in a group.

I can lead others.

Corresponding European Entrepreneurship

Competence Framework Skills [37]

"Mobilising others

Inspiring and exiting relevant partners

Geting the support needed to achieve valuable results

- Demonstrating effective communication, persuasion, negotiation, and leadership"

"Working with others

Working together and collaborating with others to develop ideas and turn them into reality

- $\quad$ Networking

- Resolving conflicts and interacting with competition positively."

\section{"Creativity}

Creating several ideas and opportunities to generate value, as well as improved solutions to existing and new challenges.

Creativity

I am creative/inventive.

I can find different ways to reach a goal.

I like to take risks.
Exploring and experimenting with innovative ways of thinking and acting

- Incorporating knowledge and resources to achieve valuable results"

"Coping with uncertainty, ambiguity \& risk

Within the value-generating process, including structured ways of testing ideas and prototypes from the early stages, to reduce risks of failure

- Handling fast-moving situations promptly and flexibly"

In research on the role of open innovation competences in individual readiness and motivations for digital transformation, a great importance is given to competences which are key factors in the formation and development of individual business activity, creating new jobs, successful entering the labor market, or building a professional career by students [22,51]. In an understudied context of central and eastern European countries, we were particularly interested in whether the origin country had an impact on the competencies of students who had chosen technical and engineering fields of study. Iivari et al. [52] argued that there is a link between digitalization transformation and young adult training, and this relationship is reflected in general country success and economic development. It is believed that sustainable growth and development comes from people's ingenuity and innovativeness, and developed best practices, which only people ready for digitization and transformation can generate. Therefore, in order to make well-informed decisions in the field of university education, it is worth creating the OI competence profile. Therefore, the objective of this qualitative research is to determine whether there are similarities or differences in student entrepreneurship, creativity, and cooperation skills. Consequently, we hypothesize that:

Hypothesis 1 (H1). The Open Innovation Competence Profile does not differ between Bulgarian, Latvian, Polish, and Ukrainian students.

Hypothesis 1a (H1a). The entrepreneurship factor does not differ between Bulgarian, Latvian, Polish, and Ukrainian students.

Hypothesis $\mathbf{1 b}$ (H1b). The cooperation factor does not differ between Bulgarian, Latvian, Polish, and Ukrainian students.

Hypothesis 1c (H1c). The creativity factor does not differ between Bulgarian, Latvian, Polish, and Ukrainian students. 


\section{Methods}

The study was based on a survey completed by the students. The sample population consisted of 2332 first-year undergraduate students from four technical universities in Bulgaria (Technical University of Sofia), Latvia (Riga Technical University), Poland (Gdansk University of Technology), and Ukraine (Lviv Polytechnic National University). Data were not statistically imputed; incomplete and invalid questionnaires were rejected. Overall, 1247 participants were male students (53.8\%), 1073 were female students (46.3), and 12 did not provide information on gender $(0.5 \%)$. The proportion is very close to the ratio of male and female students in the universities analyzed. The survey was conducted during regular lectures and seminars among first-year students in the period of October 2019 to February 2020. All students who were present received a paper version of the questionnaire. The study was part of a broader entrepreneurship-related questionnaire that had been used in the SEAS Project (Survey on Entrepreneurial Attitudes of Students), which has been an ongoing project run on several technical universities. The SEAS project members intend to acquire data from the same participants in 4-5 years to track the evolution of entrepreneurial attitudes. We have taken part in that project and used the opportunity to place questions and acquire responses related to the three aggregated competences deemed most significant for the open innovation paradigm, supported and grounded in relevant empirical OI studies.

To guarantee semantic equivalence of all the measure items, which were originally in English, a back-translation procedure was adopted to produce Bulgarian, Latvian, Polish, and Ukrainian versions of the measures. The authors, together with all the research partners, first translated the English version of the measures into their native languages. Then, the versions in native languages of the measures were independently back-translated into English by two professional translators in each language. The final questionnaire required gender, minority status, university, and field of study, and included measures to assess the OI competence profile. To assess the reliability of the measures, a pilot study was conducted among more than 180 students.

The Open Innovation Competence Profile score was measured using nine elements in three categories of factors: entrepreneurship, cooperation, and creativity. Students were asked to indicate their level of agreement with each of the statements using a five-point Likert scale. Exploratory factor analysis was performed to determine the internal structure of the scale. The principal component method was applied. Kaiser-Meyer-Olkin measure of sampling adequacy was 0.864 , above the commonly recommended value of 0.60 , and Bartlett's sphericity test was significant $\chi^{2}(36)=5087.78, p<0.001$. The Kaiser criterion was used to determine the number of factors, based on which it was established that three factors should be distinguished. Together, these factors explain 52.26\% of the variance.

After an analysis of the factors using the Varimax orthogonal rotation method, it was found that the first factor consisted of three items. They were intended to measure entrepreneurship. The factor loadings of these items were $0.83,0.82$, and 0.74 , respectively. The second factor consisted of three items that were intended to measure cooperation. The factor loadings of these items were $0.77,0.81$, and 0.66 , respectively. The last factor consisted of three items, intended to measure creativity. The factor loadings of these items were 0.73 , 0.66 , and 0.78 . No cross-loadings were observed. The three identified factors followed the expected structure. The following reliability levels were obtained (the Cronbach's alpha coefficient was computed): 0.78 for entrepreneurship, 0.64 for cooperation, and 0.74 for creativity. The second is slightly below the commonly recommended level of 0.70 , but can be considered acceptable in the case of a newly developed measure [53]. Composite scores (mean values) for each of the factors were calculated. The whole OI competence profile scale has acceptable internal reliability $(\alpha=0.812)$.

\section{Results}

In Table 2, we present descriptive statistics of our measures together with reliability levels $(n=2332)$. 
Table 2. Descriptive statistics.

\begin{tabular}{|c|c|c|c|c|c|c|}
\hline & Alpha & Mean & $S D$ & (1) & (2) & (3) \\
\hline $\begin{array}{l}\text { 1. Open Innovation } \\
\text { Competence Profile }\end{array}$ & & 3.59 & 0.61 & & & \\
\hline 2. Entrepreneurship & 0.78 & 3.18 & 0.81 & $0.86^{* *}$ & & \\
\hline 3. Cooperation & 0.64 & 3.74 & 0.71 & $0.85^{* *}$ & $0.59 * *$ & \\
\hline 4. Creativity & 0.74 & 3.85 & 0.66 & $0.80 * *$ & $0.51^{* *}$ & $0.55^{* *}$ \\
\hline
\end{tabular}

** Correlation is significant at the 0.01 level (2-tailed).

Table 2 also displays the means, standard deviations, and intercorrelations of variables included in this study. Respondents in this study rated themselves highest for creativity, followed by cooperation and entrepreneurship; overall, their OI competence profile score was at an average level of 3.59. The results of the correlation analysis indicated that all pairs of variables recorded a positive and significant correlation.

The Kruskal-Wallis test analysis was used to investigate the hypotheses formulated in this paper. The Kruskal-Wallis test is a rank-based non-parametric test that we used to ascertain if there are statistically significant differences among four groups of an independent variable (countries) on a dependent variable (rank in perception on OI competence). It is an extension of the Mann-Whitney $U$ test because it allows us to compare more than two independent groups, and it is considered the non-parametric alternative to the one-way ANOVA [54]. Since it is a non-parametric method, the Kruskal-Wallis test does not assume a normal distribution of the residuals [55]. We use the Kruskal-Wallis test to understand whether OI competence profile and its components, measured on a 5-point scale ("completely false"; "somewhat false"; "neither true nor false"; "somewhat true"; "completely true") differ based on country of origin of the university as an independent variable (group 1 "Poland", group 2 "Ukraine", group 3 "Latvia", and group 4 "Bulgaria"). H1 postulated that there were no differences in the OI competence scores of the students of the countries analyzed.

A Kruskal-Wallis $\mathrm{H}$ test determined that there was a statistically significant difference in the OI competence profile between the different countries, $\chi^{2}(3)=130.52, p=0.000$, with a mean rank OI score of 1029.65 for Bulgaria, 1060.99 for Latvia, 1063.89 for Poland, and 1400.78 for Ukraine. Thus, Hypothesis 1 was rejected.

Significant differences were also observed in the OI subscales of entrepreneurship, cooperation, and creativity:

- A Kruskal-Wallis $\mathrm{H}$ test determined that there was a statistically significant difference in entrepreneurship between the different countries, $\chi^{2}(3)=125.36, p=0.000$, with a mean rank entrepreneurship score of 1059.62 for Bulgaria, 1091.94 for Latvia, 1051.55 for Poland, and 1394.18 for Ukraine. Thus, Hypothesis 1.1 was rejected.

- A Kruskal-Wallis $\mathrm{H}$ test determined that there was a statistically significant difference in cooperation between the different countries, $\chi^{2}(3)=86.34, p=0.000$, with a mean rank cooperation score of 1158.44 for Bulgaria, 1041.92 for Latvia, 1080.88 for Poland, and 1351.20 for Ukraine. Thus, Hypotheses 1.2 was rejected.

- A Kruskal-Wallis $\mathrm{H}$ test determined that there was a statistically significant difference in creativity between the different countries, $\chi^{2}(3)=67.66, p=0.000$, with a mean rank creativity score of 949.67 for Bulgaria, 1085.50 for Latvia, 1130.48 for Poland, and 1317.35 for Ukraine. Thus, Hypotheses 1.3 was rejected.

We rejected the hypotheses of the Kruskal-Wallis tests because at least one of the samples stochastically dominates at least one other sample. Unfortunately, the test did not identify where this dominance occurs. Thus, we conducted post hoc tests to test pairwise comparisons.

The comparison between pairs allows one to conclude if there are statistically significant differences between countries. As can be seen from Tables 3-6, all pairwise comparisons with Ukraine showed such differences. 
Table 3. Open Innovation Competence Profile-pairwise comparisons.

\begin{tabular}{cccccc}
\hline \multicolumn{7}{c}{ Pairwise Comparisons of University } \\
\hline Sample 1-Sample 2 & $\begin{array}{c}\text { Test } \\
\text { Statistic }\end{array}$ & Std. Error & $\begin{array}{c}\text { Std. Test } \\
\text { Statistic }\end{array}$ & Sig. & Adj. Sig. ${ }^{\text {a }}$ \\
\hline Bulgaria-Latvia & 31.341 & 58.813 & 0.533 & 0.594 & 1.000 \\
Bulgaria-Poland & 34.232 & 51.749 & 0.661 & 0.508 & 1.000 \\
Bulgaria-Ukraine & 371.128 & 53.416 & 6.948 & 0.000 & 0.000 \\
Latvia-Poland & 2.891 & 40.768 & 0.071 & 0.943 & 1.000 \\
Latvia-Ukraine & 339.787 & 42.864 & 7.927 & 0.000 & 0.000 \\
Poland-Ukraine & -336.896 & 32.500 & -10.366 & 0.000 & 0.000 \\
\hline
\end{tabular}

Each row tests the null hypothesis that the Sample 1 and Sample 2 distributions are the same. Asymptotic significances (two-sided tests) are displayed. The significance level is $0.050 .{ }^{a}$ Significance values have been adjusted by the Bonferroni correction for multiple tests.

Table 4. Entrepreneurship factor-pairwise comparisons.

\begin{tabular}{cccccc}
\hline \multicolumn{7}{c}{ Pairwise Comparisons of University } \\
\hline Sample 1-Sample 2 & $\begin{array}{c}\text { Test } \\
\text { Statistic }\end{array}$ & Std. Error & $\begin{array}{c}\text { Std. Test } \\
\text { Statistic }\end{array}$ & Sig. & Adj. Sig. ${ }^{\text {a }}$ \\
\hline Poland-Bulgaria & -8.063 & 51.432 & -0.157 & 0.875 & 1.000 \\
Poland-Latvia & -40.383 & 40.519 & -0.997 & 0.319 & 1.000 \\
Poland-Ukraine & -342.622 & 32.301 & -10.607 & 0.000 & 0.000 \\
Bulgaria-Latvia & 32.320 & 58.453 & 0.553 & 0.580 & 1.000 \\
Bulgaria-Ukraine & 334.559 & 53.088 & 6.302 & 0.000 & 0.000 \\
Latvia-Ukraine & 302.239 & 42.601 & 7.095 & 0.000 & 0.000
\end{tabular}

Each row tests the null hypothesis that the Sample 1 and Sample 2 distributions are the same. Asymptotic significances (two-sided tests) are displayed. The significance level is 0.050 . ${ }^{\text {a }}$ Significance values have been adjusted by the Bonferroni correction for multiple tests.

Table 5. Cooperation factor-pairwise comparisons.

\begin{tabular}{cccccc}
\hline \multicolumn{7}{c}{ Pairwise Comparisons of University } \\
\hline Sample 1-Sample 2 & $\begin{array}{c}\text { Test } \\
\text { Statistic }\end{array}$ & Std. Error & $\begin{array}{c}\text { Std. Test } \\
\text { Statistic }\end{array}$ & Sig. & Adj. Sig. a \\
\hline Latvia-Poland & 38.963 & 40.386 & 0.965 & 0.335 & 1.000 \\
Latvia-Bulgaria & -116.521 & 58.262 & -2.000 & 0.046 & 0.273 \\
Latvia-Ukraine & 309.283 & 42.462 & 7.284 & 0.000 & 0.000 \\
Poland-Bulgaria & -77.558 & 51.265 & -1.513 & 0.130 & 0.782 \\
Poland-Ukraine & -270.320 & 32.196 & -8.396 & 0.000 & 0.000 \\
Bulgaria-Ukraine & 192.762 & 52.915 & 3.643 & 0.000 & 0.002 \\
\hline
\end{tabular}

Each row tests the null hypothesis that the Sample 1 and Sample 2 distributions are the same. Asymptotic significances (two-sided tests) are displayed. The significance level is 0.050 . ${ }^{\text {a }}$ Significance values have been adjusted by the Bonferroni correction for multiple tests.

Table 6. Creativity factor-pairwise comparisons.

\begin{tabular}{cccccc}
\hline \multicolumn{7}{c}{ Pairwise Comparisons of University } \\
\hline Sample 1-Sample 2 & $\begin{array}{c}\text { Test } \\
\text { Statistic }\end{array}$ & Std. Error & $\begin{array}{c}\text { Std. Test } \\
\text { Statistic }\end{array}$ & Sig. & Adj. Sig. ${ }^{\text {a }}$ \\
\hline Bulgaria-Latvia & 135.830 & 58.216 & 2.333 & 0.020 & 0.118 \\
Bulgaria-Poland & 180.816 & 51.224 & 3.530 & 0.000 & 0.002 \\
Bulgaria-Ukraine & 367.688 & 52.873 & 6.954 & 0.000 & 0.000 \\
Latvia-Poland & 44.986 & 40.354 & 1.115 & 0.265 & 1.000 \\
Latvia-Ukraine & 231.858 & 42.428 & 5.465 & 0.000 & 0.000 \\
Poland-Ukraine & -186.873 & 32.170 & -5.809 & 0.000 & 0.000
\end{tabular}

Each row tests the null hypothesis that the Sample 1 and Sample 2 distributions are the same. Asymptotic significances (two-sided tests) are displayed. The significance level is 0.050 . ${ }^{\text {a }}$ Significance values have been adjusted by the Bonferroni correction for multiple tests. 
In the case of the Open Innovation Competence Profile, we found that the group of students from Ukraine was significantly different to the group of students Bulgaria $(p=0.000)$, Latvia $(p=0.000)$, and Poland $(p=0.000)$. The other groups were not significantly different: Bulgaria-Latvia $(p=0.59)$, Bulgaria-Poland $(p=0.508)$, and Latvia-Poland $(p=0.943)$.

Analyzing only one factor from the OI competence profile, namely entrepreneurship, we observed the same pattern of differences, where only the group of students from Ukraine was significantly different to the group of students from Bulgaria $(p=0.000)$, Latvia $(p=0.000)$, and Poland $(p=0.000)$. The situation repeats also with cooperation.

In the case of the creativity factor, we found that the group of students from Bulgaria was significantly different to the group of students from Poland $(p=0.000)$. The group of students from Ukraine was significantly different to the group of students from Bulgaria $(p=0.000)$, Latvia $(p=0.000)$, and Poland $(p=0.000)$. The other groups were not significantly different: Bulgaria-Latvia $(p=0.02)$ and Latvia-Poland $(p=0.265)$.

Figure 1 shows the Kruskal-Wallis independent sample test boxplots of four Universities scores. The analysis revealed that the OI competence scores were significantly higher in the Ukrainian student group (median $(\mathrm{Md})=3.78, n=734$ ) compared to the group of Polish students ( $\mathrm{Md}=3.56, n=1026)$, Latvian students $(\mathrm{Md}=3.56, n=370)$, and Bulgarian students ( $\mathrm{Md}=3.44, n=202$ ) (Figure 1a). The same was observed in the cases of the components of the OI competence profile, where Ukraine obtained significantly higher scores in entrepreneurship $(\mathrm{Md}=3.67)$ (Figure $1 \mathrm{~b})$, cooperation $(\mathrm{Md}=4.0)$ (Figure 1c), and creativity $(\mathrm{Md}=4.0)$ (Figure $1 \mathrm{~d})$.

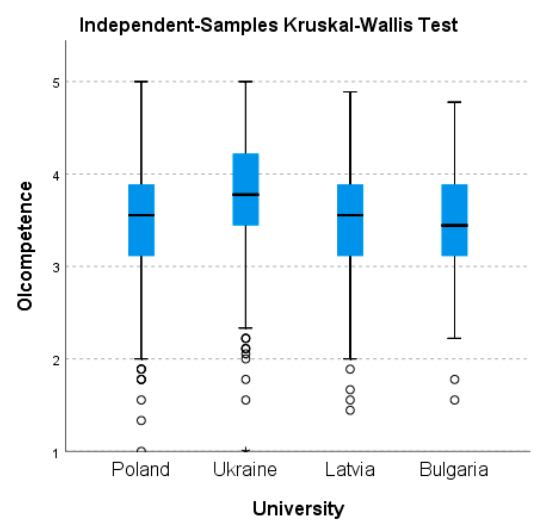

(a)

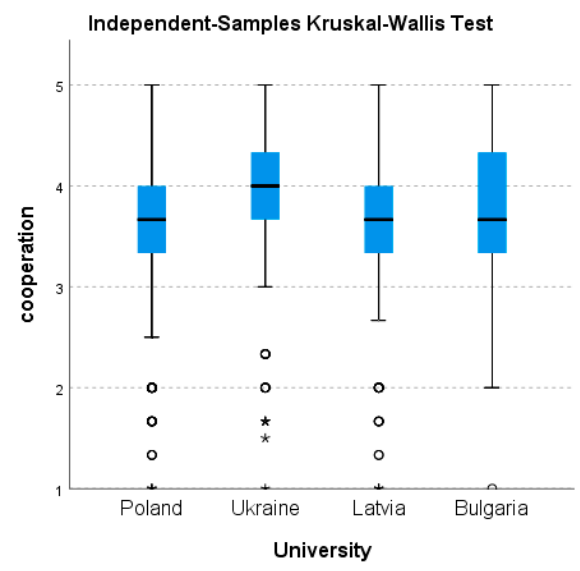

(c)

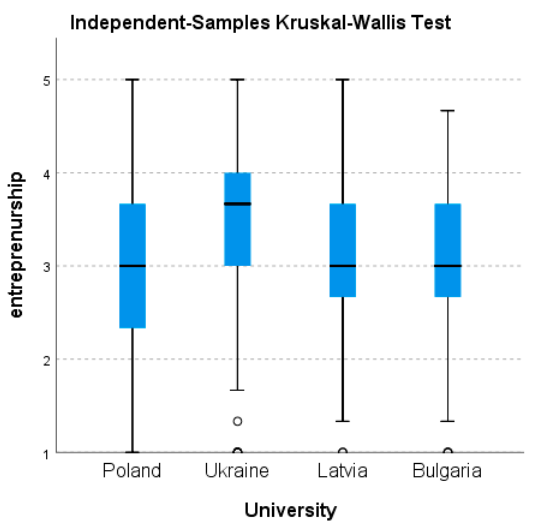

(b)

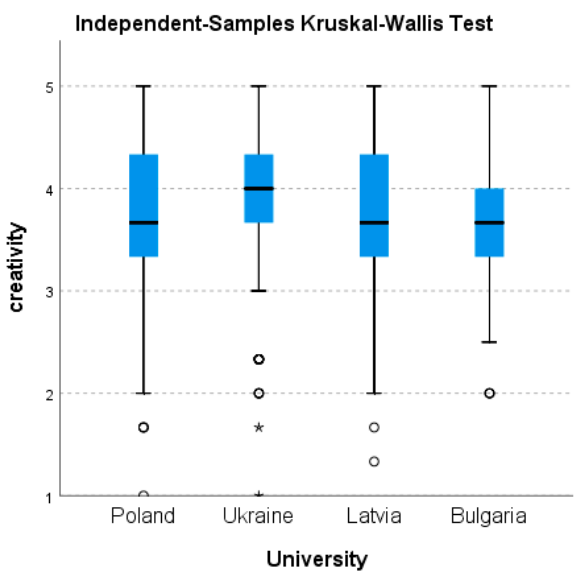

(d)

Figure 1. Kruskal-Wallis independent sample test boxplots of four categories scores including (a) OI competence score results; (b) entrepreneurship score results; (c) cooperation score results; (d) creativity score results. 


\section{Discussion and Conclusions}

Digital transformation is a key driving force of open innovation to capture and transfer knowledge and expertise within and outside of the firm's boundaries [56]. Embracing digital transformation through open innovation requires companies to determine what competencies are important and how they will be represented in the future workforce. In this article, we organized and aggregated the competencies for OI collaboration that are most grounded in empirical OI studies and developed a competency profile that organizes individual competencies in an open innovation context. Operationalizing competences on the basis of the European Entrepreneurship Competence Framework, the paper delineates an OI competency profile, which lists the core competencies to manage and accelerate the inflow and outflow of knowledge: creativity, entrepreneurship, and cooperation. Creativity is needed to transform creative solutions into products that are likely to thrive in a changing and volatile environment $[8,9,38,39,41,42,44]$. An entrepreneurial mindset is strategic for OI employees, integrating innovation and dexterity to organize business imperatives $[8,9,36,39,41,42,44-47]$. Cooperation as a competency in inter- and intra-organizational collaboration is important for OI professionals. Extended cooperation abilities are necessary for any perimeter-extending innovation activities [8,39,41,42,44,48,49]. Indeed, while these competencies as such may not be treated as an exclusive qualification for the OI professional, they help to gain and integrate external knowledge in internal processes and external utilization $[8,9]$.

By comparing the OI competency profiles of students from different universities, we answer the research question and, in doing so, complement the empirical background. We explore this profile by comparing data from students from four European universities to find differences in the distribution of OI competences between countries. University students from selected European countries were more heterogeneous in their levels of competencies. Specifically, this study revealed that Ukrainian students reported a higher intensity of OI counts in the context of a transitional economy. Regarding the links between cultural values and OI competencies, we found an interesting situation related to the context of the transitional economy, to which open innovation researchers to date have devoted relatively little conceptual and empirical attention. Students from Ukraine reported a significantly higher OI competence profile, and scored higher on its individual factors, while those from Bulgaria, Latvia, and Poland were significantly lower.

According to the Global Innovation Index (2017-2020), in recent years, Ukraine has performed very well in terms of human capital and research, being well above other lower-middle-income innovation achievers, and even above some of the high-income countries like Poland and Latvia, in particular in its performance in tertiary enrollment and knowledge creation. In addition to that, according to the 2018 Global University Entrepreneurial Spirit Students Survey (Sieger, 2019), the entrepreneurial intentions of Ukrainian students were expressed by $13 \%$ of the respondents planning to start a business in the period immediately after graduation and $58 \%$ of the respondents within five years after graduation. In comparison, $5 \%$ of Polish students expressed entrepreneurial intentions immediately after graduation, and $36 \%$ declared the desire to run their own business within five years after graduation (no data for Bulgarian or Latvian students).

The institutions, infrastructure, and framework conditions where firms operate, and the high unemployment rate in Ukraine compared to other countries under study, might play a part in the entrepreneurial attitudes of students. A possible explanation could be related to the influence of necessity-entrepreneurship prevalent in developing countries [57]. Some individuals set up businesses when they spot a business opportunity, whereas others feel forced into starting a business out of necessity because of the lack of other options in the labor market. Moreover, recent research indicates [58] that personal usage of external knowledge sources is more effective in emerging economies than in developed economies, perhaps because companies in emerging economies have less or poorer internal knowledge that employees can leverage into innovation outputs. 
This wider perspective contributes to understanding individual competencies that will serve the future OI needs of companies. The competencies indicated here manifest the corporate need for OI competencies that could be easily described, evaluated, and advanced during university education or through later training in company placement.

\subsection{Theoretical and Managerial Implications}

This article contributes to theory and managerial practice through the development of an OI competency profile and presentation of original empirical results in a multinational context. The study also provides important ground for international comparisons, pointing to the specific conditions of the phenomenon for transition economies. This paper adds to the body of knowledge on entrepreneurship education and managing competencies in an OI paradigm by identifying the OI competency level among students as future employees of European companies, and it develops an OI competence profile that is easy to use as a comparative indicator of entrepreneurial education efforts in developing competencies needed for OI adoption.

The study adds to the theory advancement by constructing, validating, and evaluating a profile score for OI competencies. This new measurement method is universal, based on the European Entrepreneurship Competence Framework, and can be used for the analysis of OI competencies in universities across different countries, as part of the analysis of entrepreneurial education, adding to the limited literature on the interrelationship between entrepreneurial education and OI management $[13,14]$. In that sense, this study is a response to calls for a further integration of the diverse levels and fields of empirical research in OI management literature [18].

On the functional side, the proposed OI competency profile contributes to the professionalization of OI governance [59] by determining different competencies connected to OI practice. Furthermore, the research is an answer to the need for an OI competency profile in entrepreneurial university education for future employees of OI-adopting companies. This paper assists in providing recommendations to higher education organizations on the development of OI-oriented curricula. At the policy level, this research constitutes a future insight into new incentive framework programs. In addition, it highlights the educational areas that should be strengthened in the policy programs targeted at European universities.

This study contributes to the current literature on digitalization transformation, open innovation, and entrepreneurship, particularly in the environment of transition countries. We proved that issuing judgments or recommendations concerning Open Innovation competences, in particular entrepreneurship, cooperation, and creativity, for quite similar countries, should be addressed separately. We showed that, despite a similar historical context, the researched countries differ significantly in many of the analytic aspects. Therefore, future research could look into the causes of these differences in more depth, to match the support and motivation system for young people and stimulate their motivation towards digitalization transformation.

In conclusion, this study builds links between management practice, open innovation, and entrepreneurial education and gives understanding for practitioners from universities, as well as managers from OI-oriented companies. The results underline the need to incorporate relevant OI competency building elements into university education and/or training of employees on the job. This paper underlines the competencies needed for future OI professionals regardless of the profile of university education and promotes OI competencies not only between business and management students but also between all fields, including engineering.

\subsection{Limitations and Future Research}

In this research, the authors focus on exploring the OI competence profile among students in four countries, so the findings cannot be applied one-to-one to other countries. Because of convenient sampling, the obtained results cannot be generalized to all students at Bulgarian, Latvian, Polish, and Ukrainian universities. Despite the student 
sample's suitability for testing hypotheses, it is possible that the sample had some constraints, as students from technological universities could be likely to be more motivated towards digitalization transformation in the form of higher OI competences compared to other people.

Due to the fact that our samples were university students, the results of our research are especially relevant not only for business and policymakers, but also for entrepreneurship education. Universities have a significant role in motivating students through providing the necessary training and courses to stimulate and encourage a more positive picture of digitalization transformation among students.

The questions used in the study were part of a broader entrepreneurship-related questionnaire that had been used in the SEAS Project (Survey on Entrepreneurial Attitudes of Students). We have taken part in that project and used the opportunity to acquire responses to questions related to the three aggregated competences deemed most significant for open innovation paradigm, based on the OI empirical research. More possible competence constructs related to OI competences could be tested in the next round of the SEAS project, providing grounds for a longitudinal OI research study.

This study is essential to determine whether European companies adopting OI will have access to the competencies required to implement OI practices in the future. It is not, however, expected that all students (as future employees) will have all the competencies at a high level. Yet, in this paper, we aim to highlight the need for universities engaged in entrepreneurial education (and firms searching to employ OI project members) to assess these dimensions along with others during the creation of a job description.

This research is exploratory and does not exhaust all the topics concerning open innovation entrepreneurial education. This study is a first step in uncovering the complexity of OI cooperation and the competencies involved. The nature of multi-layer research on IO competency invites more systematic investigation of OI competencies in relation to future diverse work environments. This research is empirical and based on a large population survey, and it represents a basis for future empirical studies researching OI competencies in Europe or other regions. Even though the sample is adequate for the conducted analyses, more calibrated and detailed analysis of national differences could be an interesting research direction, that is, the analysis of cultural variations by introducing variables measuring cultural characteristics and linking these to the OI competencies.

Author Contributions: Conceptualization, M.M. and M.L.; methodology, M.M. and M.L.; software, M.M. and M.L.; validation, M.M. and M.L.; formal analysis, M.M. and M.L.; investigation, M.M. and M.L.; resources, M.M. and M.L.; data curation, M.M. and M.L.; writing-original draft preparation, M.M. and M.L.; writing—review and editing, M.M. and M.L.; visualization, M.M. and M.L.; supervision, M.M. and M.L.; project administration, M.M. and M.L. All authors have read and agreed to the published version of the manuscript.

Funding: This research and APC was funded by Faculty of Management and Economics, Gdansk University of Technology, Poland.

Institutional Review Board Statement: Not applicable.

Informed Consent Statement: Not applicable.

Data Availability Statement: The data presented in this study are available on request from the corresponding author.

Conflicts of Interest: The authors declare no conflict of interest.

\section{References}

1. Santos, A.B.; Bogers, M.L.; Norn, M.T.; Mendonça, S. Public policy for open innovation: Opening up to a new domain for research and practice. Technol. Forecast. Soc. Chang. 2021, 169, 120821. [CrossRef]

2. European Commission. Industry 5.0, towards a Sustainable, Human-Centric and Resilient European Industry. In Policy Brief, Directorate-General for Research and Innovation; European Commission: Brussels, Belgium, 2021. 
3. World Manufacturing Forum Report. Skills for the Future of Manufacturing. 2019. Available online: https://c00e521c-fc35-464f8eef-9356e02fbfb5.filesusr.com/ugd/c56fe3_d617f7333fd347b0b2bb4a739ba72993.pdf (accessed on 3 August 2021).

4. Chesbrough, H.W. Open Innovation: The New Imperative for Creating and Profiting from Technology; Harvard Business School Press: Boston, MA, USA, 2003.

5. Fagerberg, J. Innovation: A Guide to the Literature. In Innovation: A Guide to the Literature; Oxford University Press: Oxford, UK, 2009. [CrossRef]

6. Dahlander, L.; Wallin, M. Why now is the time for "Open Innovation". In Harvard Business Review; Harvard Business Publishing: Boston, MA, USA, 2020.

7. Leckel, A.; Veilleux, S.; Dana, L.P. Local open innovation: A means for public policy to increase collaboration for in-novation in SMEs. Technol. Forecast. Soc. Chang. 2020, 153, 119891. [CrossRef]

8. Podmetina, D.; Soderquist, K.E.; Petraite, M.; Teplov, R. Developing a competency model for open innovation. Manag. Decis. 2018, 56, 1306-1335. [CrossRef]

9. Du Chatenier, E.; Verstegen, J.A.A.M.; Biemans, H.J.A.; Mulder, M.; Omta, O.S.W.F. Identification of competencies for professionals in open innovation teams. RD Manag. 2010, 40, 271-280. [CrossRef]

10. Chesbrough, H.; Vanhaverbeke, W.; West, J. (Eds.) New Frontiers in Open Innovation; Oxford University Press: Oxford, UK, 2014. [CrossRef]

11. Salter, A.; Criscuolo, P.; Ter Wal, A. Coping with Open Innovation: Responding to the Challenges of External Engagement in R\&D. Calif. Manag. Rev. 2014, 56, 77-94. [CrossRef]

12. Jeraj, M.; Marič, M.; Todorović, I.; Čudanov, M.; Komazec, S. The Role of Openness and Entrepreneurial Curiosity in Company's Growth. In Economic Interferences AE; The Bucharest University of Economic Studies: Bucharest, Romania, 2015 ; Volume 17. Available online: https:/ / www.econstor.eu/handle/10419/168922 (accessed on 3 August 2021).

13. West, J.; Gallagher, S. Challenges of open innovation: The paradox of firm investment in open-source software. RD Manag. 2006, 36, 319-331. [CrossRef]

14. Vanhaverbeke, W.; Du, J.; Leten, B.; Aalders, F. Exploring Open Innovation at the Level of R\&D Projects. In New Frontiers in Open Innovation; Chesbrough, H., Vanhaverbeke, W., West, J., Eds.; Oxford University Press: Oxford, UK, 2014; pp. 115-132. Available online: http:/ / media.wix.com/ugd/d6c2f0_c9cca80940564902877e3a4d6eeb9711.pdf (accessed on 3 August 2021).

15. West, J.; Salter, A.; Vanhaverbeke, W.; Chesbrough, H. Open innovation: The next decade. Res. Policy 2014, 43, 805-811. [CrossRef]

16. Mignon, S.; Ayerbe, C.; Dubouloz, S.; Robert, M.; West, J. Managerial Innovation and Management of Open Innovation. J. Innov. Econ. Manag. 2020, 32, 3-12. [CrossRef]

17. Enkel, E.; Bell, J.; Hogenkamp, H. Open innovation maturity framework. Int. J. Innov. Manag. 2011, 15, 1161-1189. [CrossRef]

18. Bogers, M.; Zobel, A.; Afuah, A.; Almirall, E.; Dahlander, L.; Frederiksen, L.; Gawer, A.; Haefliger, S.; Hagedoorn, J.; Hilgers, D.; et al. The open innovation research landscape: Established perspectives and emerging themes across different levels of analysis. Ind. Innov. 2017, 24, 8-40. [CrossRef]

19. Vanhaverbeke, W.; Cloodt, M. Theories of the Firm and Open Innovation. In New Frontiers in Open Innovation; Oxford University Press: Oxford, UK, 2014; pp. 256-278. [CrossRef]

20. Iglesias-Sánchez, P.P.; Jambrino-Maldonado, C.; Heras-Pedrosa, C.D.L. Training Entrepreneurial Competences with Open Innovation Paradigm in Higher Education. Sustainability 2019, 11, 4689. [CrossRef]

21. Ovbiagbonhia, A.R.; Kollöffel, B.; Brok, P.D. Educating for innovation: Students' perceptions of the learning environment and of their own innovation competence. Learn. Environ. Res. 2019, 22, 387-407. [CrossRef]

22. Hero, L.-M.; Lindfors, E.; Taatila, V. Individual Innovation Competence: A Systematic Review and Future Research Agenda. Int. J. High. Educ. 2017, 6, 103. [CrossRef]

23. Gurkov, I. Transition Economy. In Wiley Encyclopedia of Management; John Wiley \& Sons, Ltd.: Hoboken, NJ, USA, 2015; pp. 1-3. [CrossRef]

24. Chaston, I.; Scott, G. Entrepreneurship and open innovation in an emerging economy. Manag. Decis. 2012, 50, 1161-1177. [CrossRef]

25. Bogers, M.; Burcharth, A.; Chesbrough, H. Open Innovation in Brazil: Exploring Opportunities and Challenges. Int. J. Innov. 2019, 7, 178-191. [CrossRef]

26. Cornell University; INSEAD; WIPO. The Global Innovation Index 2020: Who Will Finance Innovation? Ithaca, Fontainebleau, and Geneva. 2020. Available online: https://www.wipo.int/edocs/pubdocs/en/wipo_pub_gii_2020.pdf (accessed on 3 August 2021).

27. Duda, R. Rola koncepcji path dependence w wyjaśnianiu efektywności transformacji w państwach Europy Środkowo-Wschodniej. Rocz. Inst. Eur. Srod. Wschod. 2019, 17, 143-157. [CrossRef]

28. Laursen, K.; Salter, A. Open for innovation: The role of openness in explaining innovation performance among U.K. manufacturing firms. Strat. Manag. J. 2005, 27, 131-150. [CrossRef]

29. Dahlander, L.; Gann, D.M. How open is innovation? Res. Policy 2010, 39, 699-709. [CrossRef]

30. Chesbrough, H.; Bogers, M. Explicating Open Innovation. In New Frontiers in Open Innovation; Oxford University Press: Oxford, UK, 2014; pp. 3-28. [CrossRef]

31. Hafkesbrink, J.; Schroll, M. Ambidextrous Organizational and Individual Competencies in Open Innovation: The Dawn of a new Research Agenda. J. Innov. Manag. 2014, 2, 9-46. [CrossRef] 
32. Carayannis, E.G.; Campbell, D.F.J. Open Innovation Diplomacy and a 21st Century Fractal Research, Education and Innovation (FREIE) Ecosystem: Building on the Quadruple and Quintuple Helix Innovation Concepts and the "Mode 3" Knowledge Production System. J. Knowl. Econ. 2011, 2, 327-372. [CrossRef]

33. Martinez-Conesa, I.; Soto-Acosta, P.; Carayannis, E. On the path towards open innovation: Assessing the role of knowledge management capability and environmental dynamism in SMEs. J. Knowl. Manag. 2017, 21, 553-570. [CrossRef]

34. Dabrowska, J.; Podmetina, D. Identification of competences for open innovation. In Proceedings of the International Society for Professional Innovation Management (ISPIM), Dublin, Ireland, 8-11 June 2014.

35. Sandberg, J. Understanding human competence at work: An interpretative approach. Acad. Manag. J. 2000, 43, 9-25. [CrossRef]

36. Boyatzis, R.E. The Competent Manager: A Model for Effective Performance; John Wiley \& Sons: Hoboken, NJ, USA, 1982.

37. Lahti, R.K. Identifying and Integrating Individual Level and Organizational Level Core Competencies. J. Bus. Psychol. 1999, 14, 59-75. [CrossRef]

38. Mortara, L.; Napp, J.J.; Slacik, I.; Minshall, T. How to Implement Open Innovation: Lessons from Studying Large Multinational Companies; Institute for Manufacturing, University of Cambridge: Cambridge, UK, 2009.

39. Mazur, J.; Zaborek, P. Organizational Culture and Open Innovation Performance in Small and Medium-sized Enterprises (SMEs) in Poland. Int. J. Manag. Econ. 2016, 51, 104-138. [CrossRef]

40. Hong, K.; Kim, B. Open Innovation Competency of Design Enterprises to Outsourcing Service. J. Open Innov. Technol. Mark. Complex. 2020, 6, 36. [CrossRef]

41. Sloane, P. A Guide to Open Innovation and Crowdsourcing: Advice from Leading Experts in the Field; Kogan Page Publishers: London, UK, 2011.

42. Kratzer, J.; Meissner, D.; Roud, V. Open innovation and company culture: Internal openness makes the difference. Technol. Forecast. Soc. Chang. 2017, 119, 128-138. [CrossRef]

43. Matricano, D. The State of the Art of Open Innovation Culture. In Exploring the Culture of Open Innovation; Formica, P., Curley, M., Eds.; Emerald Publishing Limited: Bingley, UK, 2018; pp. 139-162. [CrossRef]

44. Csath, M. Encouraging innovation in small and medium sized businesses: Learning matters. Dev. Learn. Organ. Int. J. 2012, 26, 9-13. [CrossRef]

45. Yun, J.J.; Zhao, X.; Jung, K.; Yigitcanlar, T. The Culture for Open Innovation Dynamics. Sustainability 2020, 12, 5076. [CrossRef]

46. Cheng, C.C.J.; Huizingh, E.K.R.E. When Is Open Innovation Beneficial? The Role of Strategic Orientation. J. Prod. Innov. Manag. 2014, 31, 1235-1253. [CrossRef]

47. Eftekhari, N.; Bogers, M. Open for Entrepreneurship: How Open Innovation Can Foster New Venture Creation. Creat. Innov. Manag. 2015, 24, 574-584. [CrossRef]

48. Behnam, S.; Cagliano, R.; Grijalvo, M. How should firms reconcile their open innovation capabilities for incorporating external actors in innovations aimed at sustainable development? J. Clean. Prod. 2018, 170, 950-965. [CrossRef]

49. Bello-Pintado, A.; Bianchi, C. Consequences of open innovation: Effects on skill-driven recruitment. J. Knowl. Manag. 2019, 24, 258-278. [CrossRef]

50. Mccallum, E.; Weicht, R.; Mcmullan, L.; Price, A. EntreComp into Action-Get Inspired, Make it Happen: A User Guide to the European Entrepreneurship Competence Framework; Bacigalupo, M., O’keeffe, W., Eds.; EUR 29105 EN; Publications Office of the European Union: Luxembourg, 2018. [CrossRef]

51. Urbinati, A.; Chiaroni, D.; Chiesa, V.; Frattini, F. The role of digital technologies in open innovation processes: An exploratory multiple case study analysis. RD Manag. 2018, 50, 136-160. [CrossRef]

52. Iivari, N.; Sharma, S.; Ventä-Olkkonen, L. Digital transformation of everyday life-How COVID-19 pandemic transformed the basic education of the young generation and why information management research should care? Int. J. Inf. Manag. 2020, 55, 102183. [CrossRef]

53. Churchill, J.G.A.; Peter, J.P. Research Design Effects on the Reliability of Rating Scales: A Meta-Analysis. J. Mark. Res. 1984, 21, 360-375. [CrossRef]

54. Ostertagová, E.; Ostertag, O.; Kováč, J. Methodology and Application of the Kruskal-Wallis Test. Appl. Mech. Mater. 2014, 611, 115-120. [CrossRef]

55. Siegel, S.; Castellan, N.J., Jr. Nonparametric Statistics for the Behavioral Sciences, 2nd ed.; Mcgraw-Hill Book Company: New York, NY, USA, 1988.

56. Saarikko, T.; Westergren, U.H.; Blomquist, T. Digital transformation: Five recommendations for the digitally conscious firm. Bus. Horizons 2020, 63, 825-839. [CrossRef]

57. Fairlie, R.W.; Fossen, F.M. Defining Opportunity versus Necessity Entrepreneurship: Two Components of Business Creation. Res. Labor Econ. 2020, 48, 253-289. [CrossRef]

58. Badir, Y.F.; Frank, B.; Bogers, M. Employee-level open innovation in emerging markets: Linking internal, external, and managerial resources. J. Acad. Mark. Sci. 2020, 48, 891-913. [CrossRef]

59. Chesbrough, H.; Brunswicker, S. A fad or a phenomenon? The adoption of open innovation practices in large firms. In Research Technology Management; Industrial Research Institute Inc.: Arlington, VA, USA, 2014; Volume 57, pp. 16-25. [CrossRef] 